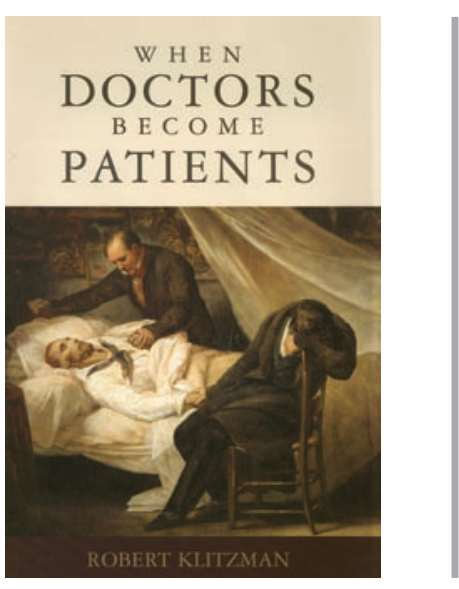

\title{
When doctors become patients
}

\author{
Robert Klitzman \\ Oxford University Press. New York, New York, USA. 2007. \\ 344 pp. \$35.00. ISBN: 978-0-19-532767-0 (hardcover).
}

Reviewed by Ira $B$. Wilson

Tufts-New England Medical Center, Boston, Massachusetts, USA.

E-mail: iwilson@tufts-nemc.org obert Klitzman's book When doctors become patients records the experiences of 70 "wounded physicians" (to use Carl Jung's term). Through these stories, the author seeks new insights into being a physician, being sick, and the functioning of the health care system in the United States in the early 21 st century.

In the introduction, Klitzman writes "Though the early states of doctor's careers have been examined ... much less attention has been given to the latter stages of medical careers and the exact boundaries of the 'doctor role.' Little is known about how they travel back to the lay world from that of being a doctor, what stages comprise their journeys, and whether their two roles change, blur, or conflict, and if so, how." Klitzman uses qualitative methods to illuminate this journey. He initially conducted 20 interviews of physicians with HIV and then recruited other physicians through the Internet, e-mail announcements, websites, word of mouth, and advertisements in newsletters. The 70 contributors lived in several cities in the United States, practiced a wide variety of specialties, ranged in age from 25 to 87 years, and had a range of medical diagnoses, including HIV infection, cancer, heart disease, Huntington disease, and bipolar disorder. The author hopes that "the lessons these doctors gained can help patients and families, current and future physicians, other health care professionals, and policymakers."

The book is organized thematically into three sections that describe the experience of becoming ill (becoming a patient), the experience of returning to work as a physician after being a patient, and how the experience of being a patient changed the ways in which these physicians practiced medicine. Thus, aspects of each physician's story surface, usually, in multiple sections. Appropriately - because the method is qualitative - Klitzman lets these physicians tell their own stories. The text is dominated by excerpts from each physician's interviews, usually 2- to 3-paragraph segments that illustrate specific points. The book's chapters are thus a series of vignettes woven together to illustrate specific themes, such as Chapter 3, "The medical self: self-doctoring and choosing doctors," Chapter 8, "Being strong: workaholism, burnout, and coping," and Chapter 11, "Us versus them: treating patients differently."

Above all, this is an honest book. To his great credit, Klitzman was able to get these physicians to talk bluntly about their experiences, how those experiences changed them, and how they tried to doctor differently as a result. While there is nobility, generosity, and kindness in these stories, there is also frustration, selfishness, resentment, and anger. Everyone will bring something different to the reading of this book, and as a result, each will take something different away.

For example, I was particularly moved and upset - by Chapter 4: "Screw-ups: external obstacles faced in becoming patients." Physicians describe the ways in which their symptoms were ignored, particularly psychiatric symptoms such as depression and anxiety; how their dignity and identity were diminished; the various incidences of poor communication that left them confused and upset; and the arrogance of treating physicians. As a practicing physician, I could only cringe as I read, thinking about the times I had been guilty of all of these same sins. For patients and their family members who read this chapter, there will be much that is all too familiar, and perhaps there will be some small reassurance that even doctors, when ill, experience these indignities.

This book, as intended, raises far more questions than it answers. This is illustrated, for example, as these wounded physicians describe how they think about their responsibilities toward their patients. On the one hand, there are condition-specific issues such as what types of care physicians with HIV should and should not participate in (i.e., should they do procedures in which there is some finite risk of bleeding and consequent infection of a patient?). But in addition, there are broader issues related to physicians' implicit commitment to "be there" for patients over time when they themselves may have, for example, a metastatic cancer. What kinds of conversations should physicians have with patients about this difficult topic? What are physicians' ethical and legal responsibilities? Here the issues faced by physicians are in some ways no different from those faced by other personal service professionals, such as lawyers or accountants, and some discussion of or reference to norms in other professions would have been helpful.

While Klitzman works hard to extract lessons for physicians and patients from these accounts, the beauty of the book for me was the directness and humanity of its stories. For that alone it is worth reading. The only aspect of these physicians' stories that I was still waiting for when the book ended was family. A theme that wove its way through every chapter was the powerful way in which the identity of "physician" shaped and often dominated these doctors' lives. I was left wondering how that identity competed with that of son, daughter, father, mother, parent, and grandparent. This is a thoughtful and carefully written book. Read it. You will not come away unaffected. 